\title{
Ciência, cientistas e democracia desfigurada: o caso Belo Monte
}

\author{
Science, scientists and blemished democracy: The Belo Monte case
}

Francisco del Moral Hernández - Graduado em Engenharia Elétrica pela Universidade Estadual de Campinas, Mestre em Energia, pelo Programa Interunidades de Pós Graduação em Energia da USP e doutorando em Energia pelo PIPGE USP - Programa Interunidades em Energia da USP. E-mail: delmoral@hotmail.com

Sonia Barbosa Magalhães - Graduada em Ciências Sociais pela Universidade Federal da Bahia, Mestre em Ciências Sociais pela Universidade Federal da Bahia, Doutora em Antropologia pela Universidade Federal do Pará e em Sociologia pela Université Paris 13. E-mail: sm.mag@globo.com

\section{Resumo}

A fronteira hidrelétrica avança sobre a Amazônia com grandes obras como Santo Antonio e Jirau no rio Madeira e de maneira decisiva através dos projetos de Belo Monte proposto na Volta Grande do Xingu, licenciado em fevereiro de 2010, e de aproveitamentos no rio Tapajós. Contudo, os grandes projetos de infra-estrutura de geração de energia nesta região revelam conflitos, disputas políticas e econômicas que evidenciam risco aos processos de licenciamento ambiental, no processo de discussão de obras que envolvem bilhões de reais e consequências ambientais e sociais de grande envergadura. Alerta-se neste artigo à deslegitimação do discurso de grupos sociais que se opõem às políticas oficiais de desenvolvimento materializadas na duvidosa e polêmica usina de Belo Monte-PA, baseado na experiência da rede Painel de Especialistas constituído para análise crítica dos Estudos de Impacto Ambiental de Belo Monte e diversos segmentos da sociedade.

\begin{abstract}
The hydroelectric frontier in the Amazon is expanding due to the construction of large projects such as Santo Antonio and Jirau in the Madeira River, proposed projects in the Tapajós River, and Belo Monte in the big bend of the Xingu River (licensed in February 2010). Large projects that generate energy in the Amazon region provoke political, social, and environmental conflicts. These conflicts affect the credibility of the Environmental Licensing Evaluation process. Discourse from social groups that oppose development policies for the Belo Monte Hydroelectric Dam project offer insight into the origins and progression of these conflicts. Criticisms of the Experts Panel Network created to analyze the Environmental Impact Assessment in Belo Monte and other sectors of the society are evaluated.
\end{abstract}

\section{Palavras-chave}

Belo Monte. Democracia. Licenciamento Ambiental. Amazônia

\section{Keywords}

Belo Monte. Democracy. Environmental Impact Studies. Amazon 


\section{INTRODUÇÃO}

A fronteira hidrelétrica avança sobre a Amazônia com grandes obras como Santo Antonio e Jirau no rio Madeira e de maneira decisiva através do projeto Belo Monte proposto na Volta Grande do Xingu, com licenciamento ambiental "condicional" concedido em fevereiro de 2010, e de aproveitamentos no rio Tapajós e seus afluentes. Projetos hidrelétricos na Amazônia Peruana e Boliviana também são discutidos por governos e empresas. Os grandes projetos de infraestrutura de geração de energia nesta região revelam conflitos e disputas políticas e econômicas que se ramificam e evidenciam risco aos processos de licenciamento ambiental, e ao próprio processo de discussão de obras que envolvem bilhões de reais e conseqüências ambientais e sociais de grande envergadura. Buscase alertar neste artigo para os riscos contidos na concentração de um discurso que tenta subsumir as violações constitucionais e infraconstitucionais, bem como deslegitimar o discurso de grupos sociais que se opõem às políticas oficiais de desenvolvimento, por meio de um argumento genérico e abstrato pautado em um suposto benefício público ou bem comum. Procura-se evidenciar, a partir da condução do processo de licenciamento da duvidosa e polêmica usina de Belo Monte (PA), como a retórica do "benefício público" é utilizada para legitimar discussões e decisões privadas que colocam o público, interessado e ameaçado, como mero expectador e as instituições como coadjuvantes.

O acompanhamento do processo de licenciamento ambiental da terceira maior hidrelétrica do mundo em capacidade instalada é revelador dos mecanismos que fazem com que uma discussão de interesse público seja esvaziada nos vários espaços institucionais que lhe garantiriam a visibilidade pública, tornando-a, na prática, discussão privada, pouco debatida e simultaneamente excludente quanto à caracterização de área diretamente afetada, população diretamente afetada e ameaçada. E, portanto, sobre os custos sociais, econômicos e ambientais que acabam por ser debitados para toda a sociedade brasileira.

No avanço sobre a natureza em busca de jazidas de megawatts, é solidária à retórica abstrata do "bem comum" a violência institucional e simbólica sobre grupos antagonistas do projeto como ribeirinhos, grupos indígenas e grupos de acadêmicos e pesquisadores que se debruçaram na decodificação das informações presentes no volumoso estudo de impacto ambiental da usina hidrelétrica de Belo Monte.

Um conjunto de evidências observadas nas várias audiências públicas do IBAMA, nos pronunciamentos públicos de proponentes da obra, bem como a fragilidade institucional na condução de controvérsias, a baixíssima circulação da informação notadamente nas áreas ameaçadas, nos conduz à constatação das 
afirmativas precedentes, traduzidas na artificialidade e no desfiguramento do processo de licenciamento ambiental.

Os processos de decisão relativos a obras de infraestrutura, que se caracterizam como estruturas de acumulação em si, colocam em evidência e provocam a discussão sobre as condições nas quais as sociedades democráticas enfrentam pelo menos quatro desafios interligados: o primeiro diz respeito à utilização das ciências e das técnicas e da interrelação entre ciência e poder - experts e governo; o segundo diz respeito à redefinição e/ou construção de um espaço público, constituído não apenas de técnicos, mas também de homens e mulheres; grupos sociais, comunidades e povos com histórias e conhecimentos diversos; o terceiro de confrontar-se com o aparato legal que rege a tomada de decisão; e, por último, especialmente no caso brasileiro, o desafio de se interrogar sobre a fidelidade dos governantes aos princípios democráticos e os mecanismos que a sociedade dispõe de fiscalização e controle.

Trata-se, portanto, de pôr em debate o processo de tomada de decisão caracterizado pela submissão ao herói governante e ao monopólio das elites técnicas e econômicas, colocando em pauta possibilidades de confrontação, seja entre saberes das elites científicas, seja entre estes e outros saberes, seja entre poder dos governantes e poderes da sociedade, seja entre risco e incerteza e história e futuro. Enfim, colocando em pauta os mecanismos para construção de um espaço público de confrontação entre especialistas e leigos, políticos e cidadãos. Relatamos no artigo um pouco da experiência que se conformou na rede Painel de Especialistas (grupo de pesquisadores originalmente constituído para realizar aanálise crítica dos Estudos de Impacto Ambiental de Belo Monte), a mobilização de diversos segmentos da sociedade, inclusive dos Ministérios Públicos Federal e Estadual, de Igrejas, ONGs ambientalistas e sobretudo dos próprios indígenas e de grupos sociais locais - mulheres, populações tradicionais, agricultores, pescadores -, tendo como foco evidências da violência institucional e simbólica no processo de licenciamento ambiental do referido projeto hidrelétrico.

\section{A FORMAÇÃO DO PAINEL DE ESPECIALISTAS}

Algumas condições se acumularam e se verificaram na formação deste painel o que permitiu um diálogo mais ou menos direto entre a comunidade científica disposta a participar de uma análise crítica do volumoso EIA de Belo Monte, ativistas, lideranças de movimentos locais de ribeirinhos, agricultores, indígenas e lideranças religiosas e de movimentos sociais do sudeste do Pará. 
Uma conjunção de fatores e recursos políticos em defesa do rio Xingu sem barragens se consolidou em análise acadêmica materializada em intervenções públicas e produção de pareceres, divulgação de resultados, circulação de informação e atividade militante, politicamente evidenciada. A atividade dos painelistas foi essencialmente de caráter voluntário. Contou com o apoio da FASE, da Rede de Justiça Ambiental, da Coalizão Rios Vivos e teve articulação, posteriormente, a partir das audiências públicas em Altamira, com a plataforma DHESCA - (Direitos Humanos Econômicos, Sociais, Culturais e Ambientais), uma articulação de 34 organizações e redes nacionais de direitos humanos ${ }^{1}$.

A existência de pré-disposição histórica dos movimentos sociais, organizações não governamentais e de grupos de pesquisadores envolvidos com a problemática das consequências ambientais e sociais dos empreendimentos hidrelétricos na Amazônia e particularmente no rio Xingu, favoreceu a composição e as atividades do grupo. Isto é, ao longo do tempo, diversos especialistas têmse mobilizado para tornar públicas as graves consequências que o barramento do rio Xingu, em seu trecho denominado Volta Grande, poderá acarretar para a importante diversidade sociocultural e biológica da região: em 1989, foi publicada "As Hidrelétricas do Xingu e os Povos Indígenas", coletânea organizada por Lucia Andrade e Leinad Ayer Santos (Comissão Pró-Índio de São Paulo); e em 2005, o livro Tenotã-mõ, organizado por Oswaldo Sevá e Glenn Switkes (disponível em http://internationalrivers.org/files/Tenotã-Mõ.pdf). Ambos, objetivando alertar a sociedade para os graves riscos sociais e ambientais inerentes ao projeto Belo Monte - vale dizer, em suas diversas versões -, sinalizavam também para a importância da expertise na construção do debate público.

Uma nova rearticulação de forças em torno do Movimento Xingu Vivo para Sempre, amalgamada pelo encontro dos Povos Indígenas em Altamira, ocorrido em maio de 2008 e que teve desdobramentos perenes como reuniões de discussão em localidades ribeirinhas e na região rural dos travessões da Transamazônica, em novembro de 2008, citadamente na Vila da Ressaca, no município de Senador José Porfírio e na comunidade São Francisco das Chagas no município de Vitória do Xingu, foi decisiva para um estreitamento de compromissos entre grupos de pesquisadores, comunidades locais e lideranças de movimentos sociais locais, nacionais e globais. Compromissos e reuniões que se estenderam por todo o ano de 2009 e perduram sob diversas formas, tempos e lugares.

1 Os recursos financeiros para viabilizar as reuniões com as populações locais, algumas passagens aéreas, organização administrativa mínima, reprografia, cópias de DVDs, ajudas de custo, não superaram a casa de R $\$ 75.000$, o que atesta o caráter voluntário, haja vista o valor das passagens áreas para um deslocamento São Paulo-Altamira, com baldeação em Belém, por exemplo, e o engajamento de 40 pesquisadores. A captação destes recursos foi dificultosa, envolvendo a FVPP - Fundação Viver produzir e Preservar, International Rivers, WWF-Brasil e Instituto socioambiental. 
O grupo formado contou com a participação de 26 pesquisadores signatários de pareceres e textos de apoio e 14 outros colaboradores. Um total de 40 especialistas que compuseram a rede - com troca de informações sobre o processo de licenciamento. Neste corpo de pesquisadores ligados a várias universidades brasileiras e a algumas estrangeiras, trabalharam antropólogos, sociólogos, biólogos, engenheiros elétricos e mecânicos, economistas geógrafos, especialistas em energia, ecólogos, ictiólogos, hidrólogos, etnólogos, zoólogos, cientistas políticos e pesquisadores da área de saúde pública e da assistência social.

O calendário imposto pela celeridade do processo de licenciamento ambiental exigiu a leitura das cerca de 20 mil páginas do EIA, em menos de 90 dias, para a produção de uma análise que provesse uma espécie de decodificação das informações e levantamento de insuficiências, para o diálogo e a capacitação de várias lideranças. Objetivava-se, em suma, realizar um exercício de tradução que favorecesse a divulgação dos detalhes do projeto, caracterizações geográficas, etc. e suas consequências sociais, ambientais e econômicas.

\section{AS PRIMEIRAS REUNIÕES PREPARATÓRIAS: DELIMITAÇÃO DAS ANÁLISES, AÇÕES, EXPECTATIVAS E POSICIONAMENTO POLÍTICO}

Com o objetivo de definir uma metodologia comum e o esboço das expectativas de um produto final, foram realizadas reuniões iniciais em Belém - PA com um bom número de pesquisadores que tinham graus distintos de aprofundamento da leitura do EIA. Posteriormente, por meio de uma rede de correio eletrônico, fizemos circular e compartilhar informações, comunicados circulares, mantendo também o intercâmbio entre os painelistas e organizações.

O diagnóstico de partida, substrato da atuação, baseava-se na constatação de que havia forte posicionamento contrário dos movimentos sociais e ambientalistas, estudiosos, desde agora e do passado, quanto a este projeto. Seguiu-se a avaliação de que, não obstante a existência deste posicionamento legítimo, que diz respeito à manutenção dos modos de vida das pessoas da região - que é sistematicamente estigmatizado como "obstáculo ao progresso" e destituído de importância - era necessário construir, a partir dos próprios dados contidos no EIA, os argumentos que atestam os riscos e a fragilidade do projeto.

Os empreendedores já utilizavam recursos econômicos e políticos - fortes e desiguais - para caracterizar a obra como de interesse nacional e construir no senso comum sua inexorabilidade e sua necessidade para remediar o problema 
energético brasileiro. Associada a essa conduta também estaria associada a presença da expertise contratada, ligada à tecnocracia estatal e à industria hidrelétrica (Dam Industry).

Partimos de um diagnóstico preliminar, com base em estudos já realizados por alguns painelistas, de que não havia clareza nos estudos quanto a números (energia, custos) e planos diretores, propostas, nem caracterização real da população e área atingida - predominavam critérios e categorizações administrativas de área de influência e do conceito de atingido. E, gravemente, ocultavam-se os riscos e efeitos da redução da vazão do rio Xingu em seu trecho denominado Volta Grande. Por acréscimo, numa espécie de "fuga para a frente", deixava implícito que a regularização adequada de vazão para o funcionamento de Belo Monte somente seria concretizada com barramentos futuros no Xingu, a montante do projeto proposto. Qualificamos esta situação como reedição dos capítulos dos projetos da década de 1980, agora com estratégia política de escrevê-los e desenvolvê-los de trás para a frente, iniciando-se por Belo Monte e construindo barramentos adicionais no sentido contrário à direção das águas do rio e no sentido contrário do que publicamente o governo apregoava.

Considerando que naquele momento já havia avaliação de que o EIA apresentava insuficiências e omissões (deliberadas ou não), politicamente nos colocamos as seguintes balizas:

1 - Manter o tom crítico (bem próximo aos dois painéis realizados em 1988 e 2005), alertando sobre a possibilidade real de surgimento posterior de no mínimo um barramento a montante do atual projeto proposto;

2 - Desconstruir/desmontar conceitos e índices utilizados para simples propaganda (índice de alagamento, custo por MW gerado ou instalado?).

3 - Evidenciar a inviabilidade econômica, social e ambiental do empreendimento, a partir da inadequação dos próprios dados apresentados.

Naquela ocasião, avaliamos que o curto tempo de que disporíamos (3 meses no máximo) para varrer cerca de 20.000 páginas do EIA, além de consultas a outras tantas páginas dos estudos de Viabilidade Técnica e Econômica, termos de referência do IBAMA, análise de correspondência trocada entre IBAMA e proponente do EIA, demandaria uma abordagem mais objetiva e disciplinada para:

- Realizar uma leitura crítica do EIA, de modo a apontar insuficiências no estudo;

- Subsidiar o posicionamentos dos movimentos sociais; 
- Não colocar nossas discussões no sentido de apontar alternativas ao projeto;

- Compilar os motivos do porquê não construir Belo Monte;

- Promover intercâmbio entre os pesquisadores na produção dos pareceres individuais;

- Objetivar o apontamento de questões essenciais e a produção dos informes.

O "produto final" deveria focalizar quatro frentes gerais:

1 - Produção de informação útil e de circulação imediata principalmente nas regiões ameaçadas e aonde quer que se discuta o projeto;

2 - Compilação de argumentos potenciais para uma ação civil pública;

3 - Compilação de argumentos úteis claros e selecionados para utilização em eventuais audiências públicas;

4 - Equalização geral de informação quanto a consequências do projeto no interior de toda a equipe, permitindo a participação ramificada de todos os membros do painel no debate público que imaginamos iria proliferar.

Os posicionamentos dos pesquisadores se aprofundaram com a leitura sistemática do EIA e com a troca de informações, mapas com posições preliminares que traziam de suas leituras e aprofundamentos individuais.

\section{PONTOS DE ESTRANGULAMENTO ANALÍTICO ENCONTRADOS NO EIA}

Conforme acima mencionado, optou-se por fazer uma leitura a partir das competências de cada um dos integrantes do painel, de modo a selecionar pontos críticos apresentados no EIA. Desse modo, não se tratava nem de uma análise exaustiva nem da produção de um EIA alternativo ou de um contra-EIA. Com estas definições e com as limitações, sobretudo do tempo que dispúnhamos, concluímos por cinco pontos que consideramos de "estrangulamento analítico do EIA":

\section{a) Os conceitos de área diretamente afetada, áreas de influência e de atingido}

Os conceitos utilizados fazem parte de acepções contidas no Manual da Eletrobrás (1988), distante, portanto, do que se exigiria de uma obra de tal envergadura e com tal ineditismo técnico (a proposta de desvio do leito original 
do rio Xingu alterando de maneira irreversível a Volta Grande do Xingu). Consideramos ser este um oportuno exemplo para evidenciar a conexão entre pressão institucional e desfiguramento do licenciamento ambiental, no qual as regiões ribeirinhas e populações ameaçadas pelo "trecho de vazão reduzida" não foram consideradas como diretamente afetadas, não obstante a sinalização de profundas alterações futuras em seus modos de vida e mesmo sem evidências da garantia de segurança hídrica. Trata-se da histórica insuficiência do reconhecimento das populações e áreas de jusante que, no caso de Belo Monte, apresenta duas áreas: uma abaixo de Pimental e outra abaixo de Belo Monte propriamente dita. A jusante de Pimental caracteriza-se por ser um trecho inédito de vazão reduzida (ou sequeiro, como queiram) de mais de $100 \mathrm{~km}$, onde vivem centenas de famílias, em localidades diversas como Garimpo do Galo, Ilha da Fazenda, Ressaca e adjacências. Esta omissão tenta, sobretudo, descaracterizar a incidência do projeto sobre terras indígenas.

A omissão, portanto, se apresenta como invisibilização das populações e de seus direitos de manter seus modos de vida ou serem reconhecidos como ameaçados. Mas, mais do que isso, tenta "contornar" a inequívoca agressão aos direitos dos Povos Indígenas, assegurados constitucionalmente. Concorre ainda para o agravamento da análise sobre as populações atingidas, a ausência de metodologias adequadas seja para a previsão da população que migraria para a área seja para a população rural já estabelecida.

\section{b) Os povos indígenas atingidos.}

"O Painel de Especialistas, sobretudo, chama atenção para a retórica sobre os impactos na Volta Grande, chamado - Trecho de Vazão Reduzida -, que oculta, dentre outros, o fato de que Terras Indígenas - Juruna do Paquiçamba e Arara da Volta Grande - são “diretamente afetadas" pela obra. E, ademais, grupos Juruna, Arara, Xipaya, Kuruaya e Kayapó, que, imemorial e/ou tradicionalmente, habitam as margens deste trecho do Rio." Esta omissão significa uma violação clara e direta aos direitos dos Povos Indígenas, assegurados tanto na Constituição Brasileira quanto na Convenção 169 da OIT - as quais determinam que os Povos Indígenas afetados sejam antecipadamente consultados por meio de procedimentos probos. Remarca ainda que os Xipaya da Terra Indígena Xipaya foram excluídos, inexplicavelmente, dos estudos. Todos os argumentos constantes dos itens "a" (acima) e "c" (abaixo) mencionados, concorriam para o que o Painel afirmava. Tanto mais porque todos os relatórios integrantes dos chamados "Estudos Etnológicos" são claros em informar que os índios foram apenas informados sobre o projeto - não consultados. 


\section{c) Os estudos hidrológicos, envolvendo níveis de água, hdirossedimentologia e implicações sobre lençol freático e desdobramentos sobre a qualidade da água, atestado pelos estudos adicionais solicitados pelo IBAMA}

Um dos aspectos mais sensíveis e inéditos deste projeto é o seccionamento do rio Xingu na ilha Pimental, o que deixaria $3 / 4$ do trecho do rio, denominado Volta Grande (cerca de $100 \mathrm{~km}$ ), com a vazão drasticamente reduzida a um mínimo de $700 \mathrm{~m}^{3}$ / s. Baseado nos dados do EIA e em simulações próprias, o Painel afirma que haverá severa diminuição dos níveis de água neste trecho seccionado do rio e diminuição drástica do lençol freático, além da redução de níveis de água de até cinco metros em trecho entre a barragem Pimental proposta e a foz do rio Bacajá. $\mathrm{Na}$ altura da cidade de Altamira, o efeito é inverso, o lençol freático se eleva e aumentam os riscos do afloramento de água na cidade. Os estudos de hidrologia do painel revelam severas omissões no EIA: inexistência de simulação e avaliação dos níveis de água a jusante da barragem Pimental; insuficiência dos estudos de sedimentologia e de análise da elevação do lençol freático. A não inclusão de uma análise da diminuição dos níveis de água do rio Xingu e de sua flutuação estacional, como consequência da redução da vazão, fez com que o Painel levantasse o alerta de que sem uma análise aprofundada das consequências da redução dos níveis de água em todo o trecho da Volta Grande, não é possível estabelecer conclusões sobre a magnitude dos impactos nesse trecho ou mesmo afirmar a suposta consistência do hidrograma de vazão reduzida.

\section{d) O prejuízo econômico do funcionamento sazonal e a necessidade de barramentos futuros}

A ociosidade operativa de Belo Monte, imposta inexoravelmente pela vazão natural flutuante do rio Xingu ao longo do ano, abre possibilidades para barramentos futuros com vista à regularização da vazão oferecida à casa de força principal. A análise de Belo Monte não pode estar dissociada da idéia de barramentos futuros no rio Xingu, que poderiam regularizar uma vazão suficiente para acionar, durante o ano todo, a potência instalada e reduzir o gap entre esta e a energia efetivamente gerada. Esta omissão na análise, simultaneamente, afeta a conclusividade sobre a viabilidade técnica e econômica da obra, bem como abre capítulos futuros de ameaças ambientais e sociais já identificadas no passado sobre grandes extensões territoriais potencialmente alagáveis.

\section{e) A perda de biodiversidade}

Alerta-se que, apenas com base no caráter irreversível do impacto sobre a ictiofauna no Trecho de Vazão Reduzida, a conclusão técnica que deveria ser formalizada no EIA é de que o empreendimento AHE Belo Monte do ponto 
de vista da ictiofauna é tecnicamente inviável, visto que irá destruir uma grande extensão de ambientes de corredeiras tanto no TVR quanto na área do lago. Não existe compensação ambiental à altura desses impactos sobre a ictiofauna. Esse trecho do rio Xingu é formado por uma série de canais, corredeiras e habitats únicos que terão sua funcionalidade perdida. A vazão reduzida irá provocar a mortandade de milhões de peixes ao longo dos $100 \mathrm{~km}$ ou mais da Volta Grande e não há medida a ser tomada que mitigue ou sequer compense este impacto. A biodiversidade presente na região se ampara na barreira geográfica que são as corredeiras e pedrais da Volta Grande que isola em duas ecorregiões os ambientes aquáticos da bacia do rio Xingu. O sistema de eclusas proposto poderia romper este isolamento, podendo causar extinção de centenas de espécies, além de impactos socioeconômicos imprevisíveis.

\section{A PARTICIPAÇÃO NAS AUDIÊNCIAS PÚBLICAS DO IBAMA}

Ocorreram apenas quatro audiências públicas, todas em setembro de 2009: Brasil Novo, no dia 10; Vitória do Xingu, no dia 12; Altamira, no dia 13 e em Belém no dia 15.

O anúncio da realização das audiências instaurou a polêmica sobre a conveniência da participação do grupo. Tínhamos a compreensão geral de que pouco espaço seria destinado à discussão substantiva. Mas, diante da heterogeneidade de opiniões entre os grupos que nos davam suporte, decidimos por uma participação engajada, que consistiu em propor questões, levantar pontos insuficientes, trazer a público a argumentação dos grupos proponentes do projeto e do EIA, assim como publicizar, sobretudo para a equipe do IBAMA que fazia a análise do EIA, os principais pontos de estrangulamento acima mencionados. Seria também uma espécie de sinalização pública de uma associação possível: a independência crítica na análise e o seu desdobramento em ação militante junto a movimentos sociais e de ameaçados.

Preparamo-nos para formular questões, fazer gravações de partes da audiência, tirar fotos, filmar, coletar informações. Na segunda e na terceira audiências públicas, em Vitória do Xingu e em Altamira, foi montada uma bancada com impressora e laptops para fazermos solicitações e anotações rápidas e formular questões nos impressos apropriados.

As audiências públicas foram extremamente longas, nas quais a exposição dos benefícios da obra, a exposição dos processos de licenciamento e os pronunciamentos de autoridades tomavam meia dúzia de horas, levando à exaustão 
o público. Verificou-se nas três primeiras audiências públicas que o debate substantivo ficou restrito às poucas pessoas que permanecem no local por pelo menos seis horas e que na prática reúne pessoas com convicções mais fortes sobre o projeto. O público mais sedento de informações se retirou antes dessa fase. Isto aconteceu de maneira indubitável na audiência de Altamira. Sobretudo, os indígenas se retiraram antes da fase de debates.

O Painel direcionou várias intervenções durante o encaminhamento oral de questões, restrito a uma pergunta por pessoa, e encaminhamos 68 perguntas por escrito, devidamente registradas em protocolo posterior.

A quarta e última audiência foi marcada pelo protesto público dos Procuradores dos Ministérios Público Federal e Estadual, já pronunciado durante a sessão realizada em Altamira. Este protesto esteve ancorado na violação da prerrogativa de participação específica dos Procuradores, como integrantes da mesa; e na absoluta falta de espaço para abrigar centenas de pessoas que desejavam participar da reunião e que eram contidas no hall de entrada do estabelecimento (Centur, em Belém) por efetivos da Força Nacional, das Polícias Federal e Militar.

Cabe relatar que, por meio de uma manobra que tentava mascarar a negação do princípio participativo que suporta a realização das audiências públicas, foi proposta pelos organizadores do evento, em Belém, a admissão selecionada de "painelistas" que se encontravam no hall, em meio à multidão excluída do recinto, inclusive grupos indígenas que, independentemente, mobilizaram-se para esta participação.

O protesto dos Procuradores, desta feita, resultou no esvaziamento da plenária, no qual se incluiu a retirada de todos os painelistas que haviam adentrado ao recinto, e, consequentemente, no esvaziamento do debate.

\section{ENCAMINHAMENTO DE PARECER AO IBAMA}

Os pareceres completos produzidos a partir do envolvimento individual dos pesquisadores com a temática das barragens propostas no Xingu, da leitura do EIA e análises sobre o processo de licenciamento ambiental, envolvendo inclusive desdobramentos dos acontecimentos das audiências públicas que já haviam sido realizadas foram encaminhados ao IBAMA e ao Ministério Público Federal, e protocolados em 1 de outubro de 2009, atendendo os prazos e formas estabelecidos.

No corpo do volume protocolado, ainda constavam críticas ao célere cronograma de disponibilização pública do Estudo de Impacto Ambiental; à 
forma parcial desta disponibilização, tendo sido o último volume disponibilizado incompleto - 48 horas antes da primeira audiência pública. Chamava-se a atenção, ademais, para que não se repetissem processos de licenciamento realizados em outros empreendimentos, que não seguiram o curso adequado, contrariando as exigências do próprio IBAMA. Alertava-se também para o agravo histórico do Tribunal de Contas da União, no qual este Tribunal adverte sobre a recorrente falta de acompanhamento das condicionantes ambientais associadas a concessões de licença e caracteriza responsabilidades sobre seu não cumprimento.

De partida, o Relatório do Painel de Especialistas abria seus resultados, alertando para os princípios democráticos já ameaçados na condução das audiências públicas e sinalizando para a impropriedade jurídica e técnica da licença ambiental condicional - um precedente perigosamente aberto com as barragens do Madeira, sobre o qual o próprio Tribunal de Contas já havia constatado a inobservância e a imprudência.

\section{DIVULGAÇÃO PÚBLICA DOS RESULTADOS}

A divulgação dos resultados deveria dar conta de várias frentes demandantes, e de outras que imaginávamos potencialmente interessadas em nossas análises. Em um primeiro patamar se situavam os movimentos sociais e organizações que solicitaram ajuda e caracterizaram a necessidade de um Painel. Munidos dos resultados poderiam se instrumentalizar com informações para fazê-las circular nos ambientes urbano,e rural, sobretudo entre riberinhos e nas aldeias ameaçadas, seja na Volta Grande seja ao longo do rio Xingu. Poderiam também utilizar seu conteúdo para fazer denuncias substanciadas relativas a aspectos de maior detalhe sobre o projeto, seja no âmbito técnico-econômico ou político, posicionando-se como interlocutor qualificado frente a um ambiente de discussão fundamentalmente regido pela tecnocracia estatal e de grandes empresas da construção civil. Esperava-se que as informações e alertas sobre a precariedade do EIA e do processo de licenciamento ambiental fluíssem e se ramificassem pelas redes constituídas pelas organizações que se posicionaram em defesa do rio Xingu.

Registra-se aqui que foram os movimentos sociais e toda a rede de organizações não governamentais articuladas pelo Movimento Xingu Vivo para Sempre que cumpriram o papel de publicizar as informações, dando visibilidade ao trabalho realizado.

Deste modo, o Painel acabou por contribuir para:

- Munir o Ministério Público Federal com informações para possível subsídio de ações civis públicas; 
- Propiciar interlocução no parlamento e com outras esferas de governo;

- Estabelecer um espaço público de discussão através das agências de notícias, interconectado com o diálogo com a academia e a possibilidade de algum debate efetivamente público com tomadores de decisão. Nesse sentido, foram feitas audiências com Juízes Federais, com a presidência do IBAMA e com o Presidente da República. Inúmeros artigos foram escritos em jornais, revistas. Entrevistas foram concedidas após a divulgação de releases e nos momentos anteriores e precedentes à concessão da licença ambiental "condicional” e nos momentos relacionados ao leilão de energia associado ao empreendimento. Muitos debates, aportes de informação em blogs, em palestras, dentro e fora de universidades, organizações de atingidos e nas próprias comunidades e aldeias ameaçadas.

- Subsidiar informações para as comunidades ameaçadas, através de cartilhas, boletins manifestos, entrevistas por rádio etc.

$\mathrm{O}$ inexistente debate entre proponentes e oponentes: fuga para a frente, clima de fato consumado e invisibilização da controvérsia como recurso político Todo o processo foi e continua a ser marcado por uma orquestração no sentido de esvaziar a discussão e o debate público sobre as consequências, não apenas sociais e ambientais, mas também econômicas, da implantação do projeto Belo Monte, especialmente nos momentos críticos: período precedente à concessão da licença ambiental prévia e no período anterior à efetivação do leilão e formação dos consórcios pleiteantes.

Após o encontro de maio de 2008 no ginásio municipal de Altamira, o primeiro debate com proponentes diretos do projeto e oponentes ocorreu somente após a concessão da licença prévia em um debate ao vivo na TV Católica em Brasília em 8 de abril de 2010. A partir da concessão da licença prévia condicional, apenas na audiência pública na Comissão de Direitos Humanos no Senado Federal (2/12/2009), sessão presidida pelo Senador Cristovam Buarque, compareceu um substituto do Presidente da FUNAI - foi severamente questionado pela índia Tuíra e por José Carlos da Terra Indígena Arara do Maia. Embora convidados, os proponentes do projeto, o Ministério das Minas e Energia, o Ministério do Meio Ambiente, Empresa de Pesquisa Energética e IBAMA estiveram ausentes:

- Nas audiências públicas no Senado Federal e na Câmara dos Deputados (7/4/2010), (ambas no âmbito de suas comissões de direitos humanos);

- Na audiência Pública no Ministério Público Federal, 4ª Câmara (1/12/2009). 


\section{A VISÍVEL PRESSÃO INSTITUCIONAL OU ELEMENTOS SOBRE A GÊNESE DA LICENÇA CONDICIONAL}

Cumpre-nos comentar que houve pressão institucional por parte da direção do IBAMA no sentido de tornar mais célere o processo de análise e concessão da licença prévia - portanto, tronada condicional. Analistas ambientais do IBAMA, responsáveis pela análise do processo de licenciamento manifestaram desconforto em conceder a licença prévia, e caracterizar a viabilidade ambiental do projeto, considerando, dois dias antes da liberação não havia elementos suficientes para atestar a viabilidade ambiental do empreendimento.

Em entrevista ao jornal O Estado de S. Paulo, de 6 de dezembro de 2009, o ex-coordenador geral de Infraestrutura de Energia Elétrica do Instituto Brasileiro do Meio Ambiente e dos Recursos Naturais Renováveis (IBAMA), Leozildo Tabajara da Silva Benjamin, afirmou que pediu demissão após uma reunião em que o ministro "tentou ensinar" os analistas ambientais do instituto a fazer licenciamento. Além dele, o diretor de Licenciamento, Sebastião Custódio Pires, também pediu demissão.

Por fim, cabe ainda mencionar o posicionamento da Advocacia Geral da União, ao afirmar que tomaria a iniciativa de processar quem dispara ações civis públicas e concede liminares contra projetos e processos governamentais - uma inequívoca intimidação ao trabalho de procuradores e juízes.

\section{DESLEGITIMAÇÃO DO DISCURSO DE GRUPOS SOCIAIS QUE SE OPÕEM ÀS POLÍTICAS OFICIAIS DE DESENVOLVIMENTO}

Os fatos acima apontados e outros relativos à condução política recente de processos de licenciamento e construção de obras de infraestrutura, desde o chamado período de redemocratização aos dias de hoje, não nos oferece elementos de evidência de que os desafios políticos para a concretização de uma sociedade democrática estejam no trilho seguro de sua superação. Por que isso não se realiza?

Vivemos em uma quadra histórica em que a democracia liberal apresenta seus limites. Paradoxalmente, elementos constituídos a partir dela, como a própria legislação ambiental, a consolidação dos direitos indígenas e de povos tradicionais, conquistados no âmbito da constituição de 1988 e regulamentações posteriores aparecem como fatores insuportáveis, quando terras ribeirinhas, rios, florestas são identificados como jazidas de megawatts. Instaura-se um campo de disputa, no qual os recursos políticos são desiguais, principalmente quando se faz sucumbir 
os parâmetros de igualdade, ainda que insuficientes, assegurados pelas leis. Neste contexto, emerge a orquestração e proliferação de chavões da estirpe de, "a democracia não pode ser um estorvo ao desenvolvimento", "forças demoníacas se opõem ao progresso", "temos que vencer os entraves, ambientais, indígenas e dos tribunais de contas".

O recurso à publicação de notas em jornais de grande circulação, tentando fazer omitir a condicionalidade da licença ambiental, anunciando datas para início da construção que, embora sucessiva e sistematicamente adiadas, tentam fazer crer a inexorabilidade do empreendimento. As disputas, as controvérsias, as ilegalidades são omitidas, assim como as pressões sobre o órgão licenciador, metamorfoseadas em infindáveis reuniões com os técnicos e inúmeros documentos incompletos, quando não dissonantes daquilo que foi demandado.

Por outro lado, o recurso pseudometodológico de invisibilidade das populações, acima mencionado, transmuta-se em reuniões parciais com indígenas em Brasília, em reuniões fechadas com prefeitos e outros segmentos, a partir dos quais inibemse mais ainda os espaços de discussão e proliferam-se as informações do fato consumado.

Não pode ser omitido, também, o fato objetivo de que a redação de um EIA, envolvendo um custo altíssimo, equipes numerosas - que segundo nosso entendimento produziram algumas descrições muito bem feitas -, não tenha produzido em seu conjunto uma avaliação que fugisse do senso comum que caracteriza as áreas ameaçadas como insignificantes na sua economia, carentes de serviços públicos e marginalizadas do progresso. Parece-nos que a redação final do estudo se afasta do trabalho mais dedicado que as equipes de pesquisadores tiveram no levantamento de campo - (excetuando-se aqui os levantamentos socioeconômicos, aos quais são pertinentes críticas mais severas quanto à metodologia e análise dos resultados).

Mencione-se ainda, a invisibilização das grandes ONGs e movimentos sociais que tem visibilidade internacional e capilaridade na divulgação de informações e em sua luta, atribuindo ao seu trabalho restrições e desabono grupos alienígenas alheios ao espaço do progresso e desenvolvimento.

O processo de invisibilização dos movimentos sociais e de enfraquecimento da resistência é reincidente a cada obra, de acordo com a conjuntura, mas, sobretudo, com a disponibilidade do apoio oficial, por meio de um conjunto de ações que fazem parte de uma determinada maneira de tratar os conflitos e assediar os ameaçados. 


\section{VIOLAÇÕES CONSTITUCIONAIS E DE TRATADOS INTERNA- CIONAIS OBSERVADAS}

O processo de licenciamento ambiental do AHE Belo Monte vem sendo conduzido violando o direito constitucional de consulta prévia às populações indígenas que serão afetadas direta e indiretamente por este empreendimento. Tal direito é garantido pela Constituição Federal e reforçado pelo artigo 6 da Convenção 1690 da OIT, ratificada e incorporada pela legislação brasileira no ano de 2003 e pelos artigos 19 e 32 da Declaração das Nações Unidas sobre Direitos dos Povos Indígenas aprovada pelo Brasil em 2006. ${ }^{2}$

Uma grave violação aos direitos humanos observada durante o processo de licenciamento ambiental: a não realização das Oitivas Indígenas, obrigatórias pela legislação brasileira e pela Convenção 169 da OIT, ratificada pelo Brasil em 2002. A convenção garante aos indígenas o direito de serem informados de maneira objetiva sobre as consequências de projetos propostos e de terem sua opinião registrada, ouvida e respeitada. Em audiência Pública na comissão de Direitos Humanos no Senado Federal, diante do diretor da FUNAI, lideranças indígenas da Volta Grande apresentaram documentação em vídeo e testemunharam que não foram feitas oitivas indígenas.

Em momento anterior (novembro de 2009), declarações de indígenas presentes no II Encontro dos Povos da Volta Grande do Xingu afirmaram não terem sido ouvidos pelo órgão indigenista (FUNAI) e que não tiveram a oportunidade de externar suas dúvidas e questionamentos ao projeto. Os indígenas reiteraram, na ocasião, que as visitas preliminares da FUNAI às aldeias, ocorridas antes da concessão do licenciamento ambiental condicional, não eram e nem substituiriam as oitivas indígenas previstas na Convenção 169 da Organização Internacional do Trabalho (LISBOA; ZAGALLO, 2010).

2 Trecho de carta endereçada ao Ao Exmo Sr. Presidente da República Luis Inácio Lula da Silva com cópia para vários ministros e presidentes do IBAMA e FUNAI Aldeia Piaraçu, 1 de novembro de 2009, 212 lideranças dos povos indígenas Mebengôkre (Kayapó), Xavante, Yudjá (Juruna), Kawaiwete (kaiabi), KisêdjÇe (Suiá), Kamaiurá, Kuikuro, Ikpeng, Panará, Nafukua, Tapayuna, Yawalapiti, Waurá, Mehinaku e Trumai, Habitantes da bacia do rio Xingu e das regiões circunvizinhas, reunidos numa assembleia na aldeia Piaraçu (TI Capoto/ Jarina) desde o dia $28 / 10 / 2009$. 


\section{COMENTÁRIOS FINAIS}

A experiência do Painel mostra a possibilidade de produzir avaliações críticas em uma parceria do movimento social com a academia. Isto é, a ação dos pesquisadores mostrou algo que parece, ao som do senso desavisado, como algo impossível - a possibilidade de posicionamento político, análise crítica e aproximação do saber cientifico ao saber tradicional. Surgem desafios adicionais para iniciativas como o do painel de especialistas, quando se constata a retração do espaço público de discussão e de circulação das idéias e mais, um constrangimento e intimidação daqueles que se posicionam contrários a projetos governamentais, sejam eles cientistas, ativistas, ribeirinhos, analistas ambientais, indígenas, procuradores, juízes. Tal desafio é principalmente importante porque traduz riscos e/ou arranhões ao processo democrático. Pressupõe todo o trabalho do Painel contribuir para a construção de um espaço público com debates qualificados, que permitam aos mais diversos atores da sociedade brasileira, em especial àqueles mais próximos de Belo Monte - espacial e politicamente - decidirem sobre os pesados ônus impostos por determinadas alternativas de produção de energia e, no limite, de opções de desenvolvimento.

Nota final: está presente em cada linha deste artigo a saudade de nosso amigo Glenn Switkes, ativista em defesa dos rios, entusiasta da formação do Painel, elo comum deste esforço em cadeia que se expressou através de sua visão humanista e sua interpretação correta da complexidade envolvida pelo seccionamento dos rios e alteração da natureza e dos modos de vida dela decorrentes. Glenn nos deixou no período compreendido entre o término das audiências públicas e a concessão da licença ambiental condicional, anterior ao carnaval de 2010. Sem saber do mal que o acometia, navegou pelo Xingu para divulgar as informações resultantes do Painel e de outras tantas informações que tinha até novembro de 2009. Suas cinzas foram espalhadas no leito do Xingu Vivo.

\section{REFERÊNCIAS}

O ESTADO de São Paulo. Minc nega pressão por licença ambiental de Belo Monte. 07 de dezembro de 2009, 13h 44, Pedro Dantas-Agencia Estado. Disponível em: http://www.estadao.com.br/noticias/economia,minc-nega-pressao-por-licenca-ambiental-debelo-monte, $478075,0 . \mathrm{htm}$

IBAMA. Parecer 114/09. Análise Técnica do Estudo de Impacto Ambiental do Aproveitamento Hidrelétrico de Belo Monte, processo n 02001.001848/2006-75. Brasília: COHID/CGENE/DILIC/IBAMA, 23 nov.,2009. 
IBAMA Parecer 06/2010. A análise técnica das complementações solicitadas no Parecer 114/09, referentes ao Aproveitamento Hidrelétrico de Belo Monte, processo $n^{\circ}$ 02001.001848/2006-75. Brasília: IBAMA, COHID/CGENE/DILIC/ IBAMA, 26 jan., 2010.

IBAMA. Nota técnica $\mathbf{n}^{\mathbf{0}} \mathbf{0 4 / 2 0 1 0}$. Atendimento ao Memo no 30/10/ GPIbama, referente ao Aproveitamento Hidrelétrico Belo Monte, processo $\mathrm{n}^{\circ}$ 02001.001848/2006-75. Brasília: COHID/CGENE/DILIC/IBAMA, 29 jan., 2010.

LISBOA, M. V.; ZAGALLO, J. G. C. Relatoria Nacional do Direito Humano ao Meio Ambiente. Relatório da Missão Xingu - violações de direitos humanos no Licenciamento da Usina Hidrelétrica de Belo Monte. Plataforma DHESCA, abril 2010.

MAGALHÃES, S.; HERNANDEZ, F. (Orgs.). Painel de Especialistas. Análise Crítica do Estudo de Impacto Ambiental do Aproveitamento Hidrelétrico de Belo Monte. 2009. Disponível:http:/ / www.internationalrivers.org/files/Belo\%20 Monte $\% 20$ pareceres $\% 20 I B A M A \_o n l i n e \% 20(3) . p d f$ 